\title{
Laboreal
}

Volume $7 \mathrm{~N}^{\circ} 1$ | 2011

Psicodinâmica e psicopatologia do trabalho

\section{Sofrimento psíquico do bailarino : um olhar da psicodinâmica do trabalho}

Sufrimiento psíquico del bailarín : una mirada de la psicodinámica del trabajo La souffrance psychique du danseur : un regard de la psychodynamique du travail

A dancer's psychological suffering: from a psychodynamics of work point of view

Marina Petrilli Segnini e Selma Lancman

\section{OpenEdition}

\section{Journals}

Edição electrónica

URL: http://journals.openedition.org/laboreal/8185

ISSN: 1646-5237

\section{Editora}

Universidade do Porto

Refêrencia eletrónica

Marina Petrilli Segnini e Selma Lancman, « Sofrimento psíquico do bailarino : um olhar da psicodinâmica do trabalho », Laboreal [Online], Volume $7 \mathrm{~N}^{0}{ }^{1} 1$ | 2011, posto online no dia 01 julho 2011, consultado o 10 outubro 2019. URL : http://journals.openedition.org/laboreal/8185

Este documento foi criado de forma automática no dia 10 outubro 2019.

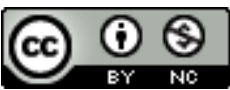

Laboreal está licenciado com uma Licença Creative Commons - Atribuição-NãoComercial 4.0 Internacional. 


\section{Sofrimento psíquico do bailarino : um olhar da psicodinâmica do trabalho}

Sufrimiento psíquico del bailarín : una mirada de la psicodinámica del trabajo La souffrance psychique du danseur : un regard de la psychodynamique du travail

A dancer's psychological suffering: from a psychodynamics of work point of view Marina Petrilli Segnini e Selma Lancman

\section{NOTA DO EDITOR}

Manuscrito recebido em : Janeiro/2011

Aceite após peritagem em : Junho/2011

\section{Introdução}

1 O trabalho artístico remonta aos primeiros registros da história da cultura ; no entanto, até o presente momento histórico é pouco analisado na perspectiva das relações que os artistas vivenciam no processo da construção do trabalho e das exigências que esse traz. Os artistas são freqüentemente representados de forma pré-conceituosa e plena de estereótipos: "egocêntricos, caricaturais, nervosos, indisciplinados, instáveis, debochados, extravagantes, obcecados por suas obras e extremamente difíceis na convivência" (Wittkower, 1991). Outra dimensão equivocada refere-se ao trabalho de criação como sendo um processo individual e solitário, indiferente à opinião do público e ao sucesso (Menger, 2005). A criação da obra artística, nestas representações, é associada a um espasmo de loucura, genialidade e melancolia individual (Prigent, 2005). 
2 No entanto, as expressões artísticas implicam em trabalho e sendo assim, são atividades reconhecidas, transmitidas, apreendidas e organizadas. E como toda a atividade, obedece a regras, insere-se numa divisão do trabalho, em organizações, profissões, relações de emprego e carreiras profissionais (Becker, 2006 cit in Segnini, 2009). Nesse sentido, a arte é compreendida pertencendo ao mundo do trabalho e, assim sendo, pode ser objeto de estudo científico para os campos teóricos que analisam o trabalho.

3 No Brasil, o trabalho artístico tem sido discutido no âmbito das ciências sociais. Destacam-se, dentre outros, alguns pesquisadores e grupos que, nos últimos anos, estudam e refletem sobre esse campo. Segnini (2007, 2008, 2009, 2010), socióloga do trabalho, coordena uma equipe que analisa o mercado e as condições de trabalho artístico. Tais pesquisas se configuram em estudos comparativos, quantitativo e qualitativo entre o Brasil e a França no que tange as condições do trabalho artístico (música e dança) nestes dois países, por meio do referencial teórico da sociologia do trabalho. Os resultados dessas pesquisas informam que o trabalho artístico é predominantemente precário e submete os artistas a uma instabilidade permanente frente às possibilidades de trabalho e de remuneração. Já no campo mais específico da dança, destacamos duas pesquisadoras. A primeira é Strazzacappa (2001, 2006), bailarina e educadora que articula nos seus estudos dança e educação. As pesquisas desenvolvidas por essa autora analisam e criticam as maneiras pelas quais está embasada a formação em dança. Em segundo lugar, Gadelha (2006) em sua dissertação de mestrado analisa o trabalho da dança sociologicamente ao longo da história, por meio do referencial teórico de Norbert Elias, Michel Foucault, Félix Guattari e Gilles Deleuze. Essa autora analisou as transformações das expressões da dança - do balé clássico ao contemporâneo - articulando-as com as mudanças na esfera da produção.

Os artistas da dança (coreógrafos e bailarinos), objeto do estudo proposto neste artigo, representam o menor grupo de trabalhadores no interior do conjunto do grupo de Profissionais de Espetáculos e das Artes, no Brasil, equivalendo a 3,3\% dos trabalhadores (Segnini, 2010). Conforme a Classificação Brasileira de Ocupações (CBO), tal grupo de artistas se subdivide em : assistente de coreografia, bailarino (exceto dança popular), coreógrafo (bailarino coreógrafo, coreógrafo bailarino), dramaturgo de dança, ensaiador de dança e professor de dança (maitre de ballet). As condições gerais do exercício deste grupo profissional são: "Trabalham nas áreas de criação, pesquisa e ensino. Suas atividades são sempre realizadas em equipe e podem se desenvolver tanto em companhias estáveis de bailado, em que predominam os vínculos formais de trabalho, estabilidade no emprego e possibilidade de construir uma carreira, como em cooperativas ou como autônomos, realizando produções independentes. Esta última é a situação da grande maioria dos profissionais, os quais, em geral, se auto-financiam, costumeiramente, exercendo atividades como professores, terapeutas etc. concomitantemente à dança" (CBO, 2002).

5 A formação profissional exigida não precisa ser necessariamente formal. $\mathrm{O}$ artista da dança está sempre em busca do aperfeiçoamento de suas técnicas e essas são múltiplas. As razões que levam um artista escolher a uma determinada técnica são inúmeras e variam conforme a necessidade de um determinado momento : procurar uma técnica cuja estética tenha a ver com o ideal de corpo do personagem, com o ideal definido pelo coreógrafo ou outra necessidade artística. Este aprendizado contínuo não é apenas encontrado no interior das instituições formais de ensino, ocorre, sobretudo, na esfera 
informal. É oriundo da experiência, das múltiplas vivências no qual o tempo é fundamental (Strazzacappa, 2006).

6 A organização do trabalho em dança exige constante reorganização dos processos de produção; impõe flexibilidade elevada ao trabalhador artista. Há necessidade da existência de um "exército artístico de reserva altamente qualificado", pré-condição para a manutenção desta forma de organização do espetáculo ao vivo, uma vez que é necessário recrutar de maneira rápida, por meio de redes de conhecimento, audições (identificação dos melhores artistas para cada espetáculo) e de acordo com diferentes possibilidades de remuneração - cachês - (Menger, 2005 cit in Segnini, 2008).

O processo de construção de um espetáculo exige dupla dimensão dos bailarinos: trabalho individual e coletivo. No trabalho individual é observado o desenvolvimento da técnica ; o conhecimento do próprio corpo, pesquisa sobre movimento, obtenção de repertório de movimento por meio da investigação individual e manutenção dos requisitos em termos biológicos. Os bailarinos e bailarinas estão em constante movimento, uma vez que o instrumento de trabalho é o corpo, é preciso mantê-lo sempre pronto para o trabalho (Segnini, 2006). É exigido desses profissionais atividades físicas diárias realizadas individualmente como: musculação, alongamento, e outras técnicas de desenvolvimento corporal. Assim como é de extrema necessidade o trabalho realizado coletivamente sob as orientações do coreógrafo, com o objetivo de se aprender o movimento de determinada coreografia (ensaios). A dança se aprende e apreende-se pelo trabalho do corpo.

o bailarino, artista cênico, encontra em seu próprio corpo o objeto para fabricar a sua arte, o seu trabalho. Talvez possa parecer redundante informar que a dança é uma atividade cujo seu instrumento principal é o corpo do artista, contudo é relevante informar que o artista da dança é desprovido de outro meio para produzir o seu trabalho. E tal instrumento - seu corpo- que o acompanha onde quer que ele esteja ; em cena ou fora dela. Observa-se, sobretudo nos bailarinos do balé clássico, cuja técnica é muito comumente aprendida desde criança, o quanto seus gestos e movimentos, mesmo fora do palco ou dos ensaios, é marcado pelas técnicas da dança clássica.

\footnotetext{
O artista cênico possui um único corpo com o qual está tanto em cena como na vida cotidiana. Todas as técnicas adquiridas para melhorar seu trabalho de performer (...) permanecem com ele, pouco importa onde ele se encontra. (...) O corpo, com sua cultura, com sua técnica, seus símbolos, constitui uma unidade. Uma vez a técnica adquirida ela lhe pertence (Strazzacappa, 2006, p. 44).
}

Os problemas de saúde física para os bailarinos expressam a relevância do corpo enquanto instrumento de trabalho. Assim, fraturas de ossos, fadiga muscular, problemas de articulações e região lombar são queixas freqüentes (Rannou \& Roharik, 2006). É por esta razão, que evidencia-se a curta duração deste trabalho; o corpo submetido a um excesso de atividade física tem um limite. É necessário, também um cuidado alimentar para que este corpo seja magro, leve e adaptável a qualquer movimento solicitado.

10 Alguns autores associam o trabalho do bailarino com o trabalho dos esportistas profissionais, no que concerne a elevada carga horária de exercícios corporais diários, somada a uma pressão por desempenho, no sentido de qualidade e precisão do movimento. Desta forma, tanto para os esportistas profissionais como para os 
profissionais da dança, a carreira é comumente curta, praticada por jovens, uma vez que tal ritmo de trabalho é mais facilmente tolerado por um corpo jovem. Em 2004, $80 \%$ dos profissionais da dança segundo o Ministério do Trabalho e Emprego, estavam na faixa etária até trinta e nove anos de idade (Segnini, 2008).

Aproximar o bailarino do esportista profissional, particularmente em termos de performance física, é oportuno porque, para ambos, esta em jogo a relação com o corpo e a breviedade na carreira. Como para o esportista, o corpo do bailarino é adaptado muito jovem em função das performances realizadas. 0 bailarino deve realizar um treinamento coletivo, organizado pelo coreografo com o objetivo de adaptá-lo fisicamente a um determinado gesto, como um treinador faz com seus atletas. Como entre os esportistas, o engajamento físico é sinônimo de risco físico (Rannou \& Roharik, 2006, p. 130, tradução livre).

11 A carreira do bailarino pode ser resumida em quatro grandes etapas : a primeira, encantamento com a atividade; muito comumente, engajam-se precocemente na profissão por meio de um ciclo de formação informal especializada, escolas de dança, por exemplo. o segundo momento é decisivo na carreira do bailarino, no qual o profissional buscará se colocar no mercado e se estabilizar enquanto artista da dança. Nesta trajetória, o terceiro período é caracterizado pela maturidade e reconhecimento profissional. No entanto, o quarto momento tende a ser marcado por complicações profissionais relacionadas, sobretudo com o corpo. Anunciando assim a saída do palco (Rannou \& Roharik, 2006).

12 A relação entre o amadurecimento profissional e a necessidade de um corpo jovem expressa um potencial conflito permanente na profissão. A angústia face a instabilidade do instrumento de trabalho está presente o tempo todo. o bailarino é sempre sujeito a um acidente de trabalho que danifica seu maior e mais precioso instrumento de trabalho. Da mesma forma, o envelhecimento é fato inerente à vida. A curta carreira do bailarino o coloca num estado de urgência profissional e numa relação com o tempo presente frequentemente exacerbadas (Rannou \& Roharik, 2006).

13 O amadurecimento profissional é um prelúdio do fim da atividade. Desta forma, é observada uma relação ambígua : quanto mais o profissional amadurece e se torna mais cônscio de suas habilidades e fragilidades, também se depara com a proximidade de ter que se retirar da cena em razão de um corpo que se fragiliza biologicamente e é menos valorizado no mundo da dança. A preocupação com o futuro profissional é freqüente entre os bailarinos. Atividades como docência, criação coreográfica, gestão e produção artística são algumas possibilidades encontradas no mercado de trabalho, para estes profissionais a posteriori, mas que já se caracterizam como novas profissões, requerem outras habilidades e qualificações.

(...) a curta carreira dos bailarinos é constituída de uma dupla tensão permanente : consolidar sua posição dentro de sua rede profissional e seu universo vocacional e, a preparação de seu futuro após a dança (Rannou \& Roharik, 2006, p. 17, tradução livre).

14 Ao analisar as características acima mencionadas sobre o trabalho do bailarino as autoras indagaram sobre os processos psíquicos engendrados por estes trabalhadores ao realizarem suas atividades. O diálogo entre a organização do trabalho em dança e a subjetividade do trabalhador bailarino é um campo que pode ser aprofundado. Com o intuito de expandir as reflexões nessa área, realizou-se um estudo cujo objetivo foi 
analisar as maneiras pelas quais os trabalhadores da dança mobilizam suas subjetividades ao buscar realizar suas atividades laborais cotidianas. Enfim, pretende-se com este artigo analisar a relação entre o trabalhador bailarino e a organização do trabalho em dança à luz do constructo teórico da psicodinâmica do trabalho (PDT). No Brasil, existe outra pesquisa realizada com este objetivo ; Santos (2008) articulou, em sua dissertação de mestrado, a relação psicodinâmica entre o sujeito bailarino e a organização do trabalho em uma companhia de dança contemporânea, em Goiás. Tal autora concluiu que a forma aparentemente naturalizada, banalizada como os bailarinos vivenciam a dor é uma estratégia coletiva de defesa face à necessidade destes trabalhadores enfrentarem e superarem a dor física para poderem trabalhar, uma vez que o trabalho da dança implica num constante e intenso trabalho do corpo. No entanto, no estudo proposto neste artigo analisou-se outra dimensão da dor que será melhor explicada no item que se refere aos resultados.

\section{Referencial teórico}

15 A psicodinâmica do trabalho (PDT) propõe que as relações no trabalho são fundamentais para a construção da subjetividade do sujeito adulto, não somente nos espaços de trabalho, mas do sujeito como um todo. Tal teoria ao articular saúde mental e trabalho na contemporaneidade elaborou categorias analíticas que demonstraram ser uma das mais significativas para analisar as relações estabelecidas entre o sujeito trabalhador bailarino e a organização do trabalho em dança, objetivo deste artigo.

16 A PDT nasce de uma prática de ação no campo e de um diálogo entre a psicopatologia do trabalho, a ergonomia, a psicanálise, a sociologia, a fenomenologia, a antropologia e a filosofia. Ela tem como pedra mestra o livro publicado em 1980, na França, intitulado Travail, usure mentale, de autoria do Christophe Dejours. Nesse livro, ainda que a psicodinâmica do trabalho não seja assim nomeada, o autor esboça as premissas norteadoras da teoria. O autor propõe a clínica do trabalho, cujo objetivo é compreender o conflito entre a organização do trabalho e o funcionamento psíquico do trabalhador. A PDT questiona como as pessoas, apesar de submetidas a diversos constrangimentos relacionados às condições e à organização do trabalho conseguem trabalhar sem adoecer psiquicamente. Como fazem os trabalhadores do ponto de vista psíquico para realizarem suas atividades laborais, apesar de todas as dificuldades que enfrentam no trabalho? A partir deste questionamento é elaborada a complexa categoria normalidade sofrente que informa as estratégias defensivas, construídas individual ou coletivamente, contra o sofrimento patogênico vivenciado no trabalho. Tal categoria pode ser considerada um divisor de águas entre a PDT e a psicopatologia do trabalho. A psicopatologia do trabalho é uma disciplina elaborada nos anos 1950-1960, na França, por autores como L. Le Guillant, C. Veil, P. Sivadon, A. FernandezZoila, J. Bégoin (Billiard, 2001). Tal teoria pressupunha que a doença mental no trabalho é causada pelos constrangimentos impostos pela organização do trabalho ou por problemas psíquicos pré-existentes das pessoas. A psicodinâmica do trabalho deixa de focalizar o sofrimento no trabalho como produto de uma relação de causa e efeito das relações de poder vivenciadas na esfera da exploração do trabalho sobre a subjetividade do trabalhador, e passa a analisar o sofrimento e as defesas contra os aspectos nocivos á saúde mental da organização do trabalho. A normalidade sofrente, por sua vez, expressa a racionalidade subjetiva das condutas e das ações dos trabalhadores. A psicodinâmica do 
trabalho é germinada nesta relação com o trabalhar, entendida como uma relação indissociável entre o sujeito que trabalha e o ato de trabalhar com todas as relações inerentes a esse confronto e não somente entre a patologia e a normalidade (Dejours, 2004a).

17 Partindo da concepção de sujeito, tal como compreendido pela psicanálise, a PDT compreende que o trabalhador não é passivo frente aos constrangimentos organizacionais, sendo capaz de se proteger dos efeitos deletérios da organização do trabalho sobre a saúde mental por meio de estratégias defensivas. Segundo a psicanálise, a defesa e os mecanismos de defesa se constituem em processos inconscientes que tem por função evitar o desequilíbrio psíquico, auxiliando o ego na elaboração dos conflitos psíquicos. Desta forma, o ego mantém certo controle face às representações e afetos insuportáveis e inaceitáveis para ele (forças pulsionais). Neste sentido, a defesa e os mecanismos de defesa são fundamentais para a manutenção da saúde psíquica do sujeito, no entanto o uso excessivo de tais processos pode comprometer o equilíbrio psíquico, uma vez que originam sintomas. Mecanismos de defesa e defesa, para a psicanálise, são conceitos complexos que ora participam de processos da construção do aparelho psíquico, ora são processos que auxiliam na manutenção da saúde psíquica, além do que estão na base da construção dos sintomas (Laplanche e Pontalis, 2001 ; Schmid-Kistkis, 2002). Desta forma, Dejours ao analisar a maneira pela qual o trabalhador se defende psiquicamente das dificuldades impostas pela realidade da organização do trabalho, define tal processo como construção de estratégias de defesa e não como mecanismos de defesa, uma vez que este último tem outras implicações e sentidos na teoria psicanalítica, conforme explicitado.

É importante salientar que para a PDT as estratégias de defesa, não são analisadas como aspectos positivos que mantém o trabalhador produtivo apesar de todas as dificuldades encontradas no trabalho, mas como um processo que desencadeia no estado de normalidade sofrente, que não é, em hipótese alguma, ausência de sofrimento. Ela expressa, aparentemente, a idéia de equilíbrio saudável entre as pessoas. Afinal, ela permite que os trabalhadores pertencentes a uma determinada organização, mesmo que submetidos a sofrimentos patogênicos, realizem suas atividades, sem causar prejuízo ao processo de trabalho. No entanto, tal normalidade é mantida à custa de muito sofrimento. A normalidade sofrente não deve ser confundida com estado saudável (Lancman \& Uchida, 2003).

19 As estratégias de defesa e a normalidade sofrente possuem ainda outra função que, todavia, pode ser explorada pelas organizações do trabalho ; elas atenuam o sofrimento, sem proporcionar a cura. Elas bloqueiam a reflexão do trabalhador sobre o seu sofrimento. "Assim, as estratégias defensivas desempenham o papel de freio à reapropriação, à emancipação e à mudança." (Dejours, 2004a, p. 54). Desta forma, "o que é explorado pela organização do trabalho não é o sofrimento, em si mesmo, mas principalmente os mecanismos de defesa utilizados contra este sofrimento" (Dejours, 1987, p. 119).

20 O sofrimento, contudo, para a PDT, não é somente fonte de desorganização psíquica, ele é entendido, também, como inerente ao trabalho, uma vez que frente aos desafios de realizar algo novo, o sujeito entra em um conflito,um estado de angústia, se ele conseguirá realizar ou não tal atividade. E ao se lançar na resolução deste conflito, o sujeito cria o novo. A criação e a realização de si mesmo no trabalho estão intimamente relacionadas e propiciam o prazer no trabalho. Desta forma, para a PDT, o sofrimento 
no trabalho se desdobra em duas possibilidades: sofrimento criador, quando o indivíduo tem meios para se desenvolver e sofrimento patogênico quando o mesmo não oferece saídas e alternativas de superação.

21 A normalidade sofrente é formada pelas estratégias defensivas contra o sofrimento patogênico vivenciado no trabalho, decorrente de um equilíbrio instável, precário entre esse sofrimento e as defesas contra ele. Nesse processo psíquico a elaboração inconsciente das estratégias de defesa é fundamental para que o sujeito possa viver sem ter que se afrontar com o sofrimento desestruturante. Quando o sofrimento patogênico não gera uma ruptura do equilíbrio psíquico, trazendo à tona uma descompensação psicopatológica, é porque contra ele o sujeito empregou poderosas defesas que o permitiram controlá-lo (Dejours, 1999).

22 A patologia é trazida à tona quando as estruturas defensivas que permitiam a manutenção da normalidade sofrente não mais a sustentam. Ou seja, o aparelho psíquico não consegue mais se equilibrar contra as forças desestruturantes oriundas do sofrimento vivenciado no trabalho. Depressão, estresse, drogadição, burn-out, karoshi (morte súbita no local de trabalho), suicídio no local de trabalho (Dejours \& Bégue, 2010) são patologias que tem sido relacionadas com o sofrimento psíquico excessivo vivenciado no trabalho. Conforme, resume pesquisadores da área da PDT, no Brasil :

(...) A patologia surge quando se rompe o equilíbrio e o sofrimento não é mais contornável. Em outros termos, quando um certo trabalhador utilizou todos os seus recursos intelectuais e psico-afetivos para dar conta da atividade e demandas impostas pela organização e percebe que nada pode fazer para se adaptar e/ou transformar o trabalho (Lancman \& Uchida, 2003).

\section{Método}

Esta pesquisa se insere no âmbito da pesquisa qualitativa e se configura num estudo de caso - o do Balé da Cidade de São Paulo (BCSP). Tal companhia de dança foi criada em 1968 como um dos corpos estáveis do Theatro Municipal de São Paulo, vinculado à Prefeitura da Cidade de São Paulo. Em 1974, o BCSP se transformou em uma companhia de dança contemporânea. Essa mudança, não apenas representou a realização de um trabalho artístico diferenciado em relação ao balé clássico, mas implicou, também, em novas formas de relações no trabalho. A partir de então, os bailarinos não são mais diferenciados hierarquicamente, tal como se organizavam as companhias de balé clássico e todos eles passam a receber o mesmo salário. Apesar de uma aparente estabilidade, os contratos são temporários, renovados periodicamente, na maioria dos casos de seis em seis meses. Esse grupo de trabalhadores, na medida em que não são contratados formalmente segundo a legislação trabalhista brasileira (CLT Consolidação das Leis do Trabalho), não tem direitos sociais assegurados, tais como férias, licença maternidade/paternidade, afastamento remunerado por doença, aposentadoria entre outros benefícios assegurados pelas leis trabalhistas brasileiras.

No entanto, a situação acima descrita significa, no instável mundo do trabalho em dança, estabilidade financeira e profissional para os bailarinos. Essa situação faz com que pertencer ao grupo dos bailarinos profissionais do BCSP, seja, no meio artístico, altamente almejado, tanto pelo seu reconhecimento social, quanto pela competência artística atribuída a seus bailarinos. Além do que o BCSP representa um espaço de 
trabalho cujas condições de trabalho são consideradas diferenciadas positivamente pelos artistas, na medida em que lhes é possibilitado acesso a um trabalho permanente. As autoras escolhem realizar esta pesquisa no BCSP, uma vez que, conforme descrito acima, esse se constitui em um espaço de trabalho no campo da dança que permite que um coletivo de bailarinos sobreviva de dança, sendo, portanto, caracterizado como um grupo de profissionais da dança.

As técnicas escolhidas foram entrevistas individuais e observação do processo de trabalho. As entrevistas realizadas foram abertas, duraram em média noventa minutos, foram registradas em gravador digital e transcritas pelas autoras. Quatro bailarinas, dois bailarinos, coreógrafo, a dramaturga e uma fisioterapeuta da companhia analisada participaram voluntariamente. $O$ objetivo de realizar as entrevistas com o coreógrafo, a dramaturga e com a fisioterapeuta foi buscar obter maior compreensão do campo pesquisado. As análises contidas neste artigo são fundamentalmente oriundas das falas dos bailarinos e bailarinas do BCSP e da observação do processo de trabalho.

Quadro I. Dados gerais dos entrevistados

\begin{tabular}{|c|c|c|c|c|c|c|c|}
\hline Entrevistas & $\begin{array}{l}\text { Ocupação no } \\
\text { BCSP }\end{array}$ & \begin{tabular}{ll|} 
Balé & Canela \\
Fina &
\end{tabular} & Sexo & Idade & Formação & $\begin{array}{l}\text { Iniciou } \\
\text { na } \\
\text { Dança }\end{array}$ & $\begin{array}{l}\text { Tempo } \\
\text { no } \\
\text { BCSP }\end{array}$ \\
\hline Bailarina I & Bailarina & Elenco 1 & Mulher & $\begin{array}{l}34 \\
\text { anos }\end{array}$ & $\begin{array}{l}\text { Balé } \\
\text { Clássico }\end{array}$ & $\begin{array}{l}9 \text { anos } \\
\text { de } \\
\text { idade }\end{array}$ & $\begin{array}{l}15 \\
\text { anos }\end{array}$ \\
\hline Bailarina II & Bailarina & Elenco 2 & Mulher & $\begin{array}{l}37 \\
\text { anos }\end{array}$ & $\begin{array}{l}\text { Balé } \\
\text { Clássico }\end{array}$ & $\begin{array}{l}9 \text { anos } \\
\text { de } \\
\text { idade }\end{array}$ & 8 anos \\
\hline Bailarina III & Bailarina & 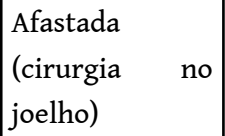 & Mulher & $\begin{array}{l}29 \\
\text { anos }\end{array}$ & $\begin{array}{l}\text { Balé } \\
\text { Clássico }\end{array}$ & $\begin{array}{l}14 \text { anos } \\
\text { de } \\
\text { idade }\end{array}$ & 2 anos \\
\hline Bailarina IV & $\begin{array}{l}\text { Bailarina } \\
\text { membro } \\
\text { direção do BCSP }\end{array}$ & $\begin{array}{ll}\text { Direção do } \\
\text { BCSP }\end{array}$ & Mulher & $\begin{array}{l}48 \\
\text { anos }\end{array}$ & $\begin{array}{l}\text { Balé } \\
\text { Clássico }\end{array}$ & $\begin{array}{l}13 \text { anos } \\
\text { de } \\
\text { idade }\end{array}$ & $\begin{array}{l}30 \\
\text { anos }\end{array}$ \\
\hline Bailarino I & Bailarino & Elenco 2 & Homem & $\begin{array}{l}31 \\
\text { anos }\end{array}$ & $\begin{array}{l}\text { Balé } \\
\text { Clássico }\end{array}$ & $\begin{array}{l}13 \text { anos } \\
\text { de } \\
\text { idade }\end{array}$ & 7 anos \\
\hline Bailarino II & Bailarino & Elenco 2 & Homem & $\begin{array}{l}32 \\
\text { anos }\end{array}$ & $\begin{array}{l}\text { Balé } \\
\text { Clássico }\end{array}$ & $\begin{array}{l}15 \text { anos } \\
\text { de } \\
\text { idade }\end{array}$ & 8 anos \\
\hline Coreógrafo & $\begin{array}{l}\text { Coreógrafo } \\
\text { convidado }\end{array}$ & Coreógrafo & Homem & $\begin{array}{l}33 \\
\text { anos }\end{array}$ & Dança & $\begin{array}{l}13 \text { anos } \\
\text { de } \\
\text { idade }\end{array}$ & $\begin{array}{l}3 \\
\text { meses }\end{array}$ \\
\hline
\end{tabular}




\begin{tabular}{|l|l|l|l|l|l|l|l|}
\hline Dramaturga & $\begin{array}{l}\text { Dramaturga } \\
\text { convidada }\end{array}$ & Dramaturga & Mulher & $\begin{array}{l}32 \\
\text { anos }\end{array}$ & Teatro & $\begin{array}{l}15 \text { anos } \\
\text { de } \\
\text { idade }\end{array}$ & $\begin{array}{l}3 \\
\text { meses }\end{array}$ \\
\hline Fisioterapeuta & Fisioterapeuta & Fisioterapeuta & Mulher & $\begin{array}{l}45 \\
\text { anos }\end{array}$ & Fisioterapia & & 8 anos \\
\hline
\end{tabular}

As entrevistas foram analisadas segundo o método de análise de conteúdo proposto por Bardin (1977). Escolhemos a análise de conteúdo por ser um método de pesquisa reconhecido pelo meio científico e uma maneira de analisar com acuidade a fala dos trabalhadores que participaram desta pesquisa. 0 objetivo da análise de conteúdo é dividir as falas dos entrevistados em categorias e temas, de tal forma que no final dessa minuciosa categorização das falas possam ser realizadas generalizações e reflexões teóricas sobre o observado.

Categorizar implica isolar elementos para, em seguida, agrupá-los. As categorias devem ser: (a) exaustivas, isto é, devem permitir a inclusão de praticamente todos os elementos, embora nem sempre isso seja possível ; (b) mutuamente exclusivas, ou seja, cada elemento só poderá ser incluído em uma única categoria ; (c) objetivas, isto é, definidas de maneira precisa, a fim de evitar dúvidas na distribuição dos elementos; (d) pertinentes, ou seja, adequadas ao objetivo da pesquisa (Vergara, 2006, p. 18).

O método proposto por Bardin prevê que as categorias analíticas devem emergir do próprio discurso dos entrevistados. O material coletado permitia diversos focos de análise. Nessa pesquisa, opta-se por privilegiar e destacar somente algumas das categorias relacionadas ao sofrimento psíquico dos bailarinos correlacionando-as com a categoria estratégia de defesa elaborada pela PDT e descrita na introdução deste artigo. O quadro abaixo explicita os temas que nortearam a categorização das entrevistas analisadas. A partir da análise destes temas elegeram-se alguns que demonstraram ser mais relevantes. Realizou-se uma articulação entre tais temas e a psicodinâmica do trabalho.

Quadro II. Temas selecionados para analisar as entrevistas

\begin{tabular}{|c|c|}
\hline Temas de análise & Subtemas \\
\hline $\begin{array}{l}\text { O sofrimento no } \\
\text { trabalho }\end{array}$ & $\begin{array}{l}\text { A busca pela perfeição } \\
\text { A constante submissão ao julgamento do outro } \\
\text { A constante pressão pelo alto desempenho } \\
\text { A frustração de não ser escolhido para o elenco principal a cada novo } \\
\text { espetáculo } \\
\text { A competitividade } \\
\text { O erro no trabalho } \\
\text { O convívio com a dor (física) }\end{array}$ \\
\hline
\end{tabular}

A observação do processo de trabalho foi realizada durante três meses. Neste período foi possível acompanhar o processo de elaboração de um espetáculo de dança na 
companhia estudada, do seu início até a estréia do espetáculo. As observações foram realizadas semanalmente e sempre tiveram a duração de um dia completo de jornada de trabalho, ou seja, de oito horas. Essas observações foram registradas em cadernos de campo e em fotos digitais. Utilizou-se a observação do processo de trabalho com o intuito de aprofundar o conhecimento das relações sociais estabelecidas nos processos de elaboração do trabalho em dança que ainda é pouco analisado, no Brasil. A observação do processo de trabalho permitiu identificar valores do grupo e aspectos do relacionamento entre os membros do coletivo que passam despercebidos na fala dos trabalhadores (Vergara, 2006).

31 A escolha e a combinação dos dois métodos (observação do processo de trabalho e análise de conteúdo das entrevistas) ocorreu com intuito de oferecer a maior quantidade de informações sobre o grupo estudado, sendo um método complementar ao outro no que tange os dados encontrados.

\section{IV.Resultados}

Para que a discussão dos resultados da pesquisa descrita neste artigo possa ser melhor compreendida é necessário ressaltar algumas características observadas da organização do trabalho no BCSP. Desta forma, o item IV está dividido em dois tópicos : IV.I - A organização do trabalho do BCSP, que por sua vez está dividido em três sub-tópicos : a. o processo de trabalho, b. relações no trabalho e c. pressão pela perfeição. Já o tópico IV.II - O bailarino e as estratégias de defesa mobilizadas ao trabalhar, refere-se a análise dos dados à luz da PDT, esse tópico foi subdividido em três : a."eu ligo o profissional", b. "bailarino tem ego" e, por último o c. valorização da dor.

\section{IV.I A organização do trabalho do BCSP}

\section{A. 0 processo de trabalho}

33 A agenda de espetáculos do BCSP é definida pela direção da Companhia em conjunto com a direção do Theatro Municipal de São Paulo. A definição das coreografias é realizada pela direção do BCSP, podendo ser selecionada coreografia do repertório da Companhia ou mesmo uma nova coreografia, criada especialmente para o BCSP, por um coreógrafo convidado. Este foi o caso do processo de trabalho observado nesta pesquisa.

Uma vez definida a coreografia, o processo de trabalho para a construção de um espetáculo, no BCSP, pode ser resumido em três etapas. Primeiro, a escolha do elenco. Em segundo lugar, os ensaios, momento em que a coreografia é transmitida aos bailarinos e, ás vezes, reelaborada de acordo com as características físicas e/ou técnicas dos bailarinos. A montagem da obra coreográfica ocorre por meio desses ensaios, os quais representam um longo período de trabalho na preparação de um espetáculo. A terceira etapa consiste na apresentação do espetáculo em si, na concretização da obra artística propriamente dita.

No BCSP, a cada nova montagem de espetáculo um coreógrafo ou coreógrafa é convidado, desta forma a cada nova construção coreográfica, os bailarinos do BCSP são confrontados com uma nova forma de trabalhar. Outra característica da organização do trabalho analisada é que a cada novo espetáculo o elenco é dividido em dois; elenco $1 \mathrm{e}$ elenco 2. 0 elenco 1 é constituído pelo grupo de bailarinos e bailarinas considerados, 
pelo coreógrafo e pela direção do BCSP, mais apto para realizar a coreografia. Já o elenco 2 é representado pelos substitutos do elenco 1. Cada bailarino do elenco 1 tem o seu representante no elenco 2. Esta divisão do grupo é, comumente, geradora de angústia, frustração e competitividade. Ser do elenco 2 é considerado pelos bailarinos um demérito. $O$ bailarino do elenco 2 terá que estar tão preparado quanto o bailarino do elenco 1, porém, pode ser que não venha a participar da apresentação.

o coreógrafo e o assistente de coreografia são os responsáveis pelo padrão e o controle do movimento, pela qualidade da obra coreográfica, estão atentos à técnica de cada bailarino, se preocupam com a coesão do grupo na execução da dança, assim como adequam os tempos da dança com relação à música. $O$ trabalho da dança é detalhista, minucioso e exigente. É um trabalho realizado sob o constante olhar crítico do coreógrafo, dos assistentes de coreografia e, também, da direção.

Durante os ensaios, os bailarinos frequentemente são interrompidos, para que tenham seus movimentos corrigidos. O reconhecimento positivo do trabalho realizado é comumente expresso pelo coreógrafo e seus assistentes no final dos ensaios, porém, esse reconhecimento é comumente acompanhado por uma lista de críticas e apontamentos que indicam correções e modificações. É observado que as correções são propostas para o grupo e para cada bailarino individualmente, as quais, entretanto, deverão ser sempre realizadas coletivamente. As críticas individuais são informadas coletivamente, com o intuito de possibilitar a todos um processo de aprendizagem de como realizar a obra coreográfica. Os bailarinos do elenco 2 participam desse processo, porém ficam como uma espécie de sombra do elenco 1, ou seja o coreógrafo e os assistentes de coreografia não o corrigem durante os ensaios do elenco 1. Haverá, no entanto, um momento no qual somente o elenco 2 ensaiará e assim receberá a atenção do coreógrafo.

\section{B. Relações no trabalho}

Observou-se que apesar de não existir uma hierarquia formal entre os bailarinos há uma relação de submissão ao coreógrafo e à direção artística da companhia. $O$ bailarino é responsável pelo movimento e buscará, no seu próprio corpo, uma maneira de alcançar o que lhe está sendo solicitado. É o corpo deste bailarino que sofrerá lesões ou ficará dolorido, não somente pelo excesso de trabalho com o corpo - sete horas diárias -, mas também pela pressão sofrida para atingir uma execução virtuosa. Como informa a bailarina I, entrevistada nesta pesquisa :

(...) a gente tem muito pouca inteligência para se mexer dentro de uma companhia, porque a gente vai ao massacre na força (bailarina I, BCSP, $30 / 05 / 08)$.

39 A demanda do coreógrafo é vivenciada como lei, são raros os momentos de contestações, ou mesmo, simples sugestões dos bailarinos sobre o movimento que executam. É um processo de trabalho que implica em obediência, no sentido de sujeitar - se à vontade do outro, em disciplina, no sentido de submissão a um regulamento e em busca pela perfeição do movimento que, por sua vez, está intrinsecamente relacionada à busca por um determinado corpo para o trabalho. 


\section{Pressão pela perfeição}

40 Esta constante procura pela perfeição e exatidão do movimento é almejada pela organização do trabalho, e também pelo próprio bailarino. É observada uma íntima relação entre a auto-exigência do bailarino e a exigência da organização, sendo difícil uma diferenciação entre elas.

(...) Eu me cobro muito. (...) A gente tem um cotidiano muito duro, muito exigente. (...) Então, a saúde mental e física vai para o chinelo (bailarina I, BCSP, 30/05/08).

O grau de exigência do bailarino é (...) gigante (bailarina IV, BCSP, 21/05/08).

41 Observa-se uma organização na qual a disciplina é almejada e valorizada; a pontualidade, a perfeição do movimento e a exigência por corpos esteticamente e fisicamente perfeitos são cobrados diariamente destes profissionais. Existe uma constante exigência por uma qualidade e precisão do movimento, assim como a manutenção do corpo enquanto instrumento de trabalho. Nota-se uma permanente busca pela perfeição.

Os bailarinos são profissionais que estão constantemente trabalhando sob o olhar do outro. Inicialmente, ainda nos ensaios, estão sob o olhar da direção artística, do coreógrafo e do colega. Durante o espetáculo somam-se os olhares do público e da crítica especializada.

\section{IV.II. O bailarino e as estratégias de defesa mobilizadas ao trabalhar}

Esse grupo de profissionais analisados informam, nas entrevistas, que iniciam suas atividades no mundo da dança, ainda crianças ou adolescentes. Tal atividade é, primeiramente, vivenciada como um lazer. É a satisfação que o movimento proporciona que impulsiona estes sujeitos a optarem pela dança como profissão, assim como a idéia glamourosa que a profissão representa na sociedade. 0 autoconhecimento, a superação de si mesmo, a identificação com a arte alcançada pelo sujeito ao dançar é fonte de prazer para o bailarino. Prazer que está relacionado a satisfação no trabalho; a identificação com o que está sendo produzido, o sentimento de reconhecimento pelos colegas, pela hierarquia e pelo público. Neste sentido, o trabalhador bailarino é um artista ; apaixonado pelo seu mêtier. No entanto, também foi possível observar que a dança para deixar de ser lazer e ser um ofício exige dos bailarinos um aprendizado para o trabalho. É preciso aprender determinadas técnicas, métodos, linguagens e estilos de movimento. É preciso um controle estético do corpo enquanto instrumento de trabalho. É preciso aprender a se submeter as regras da organização do trabalho. É preciso seguir determinada coreografia. É preciso saber lidar com a competitividade velada, mas constante. É preciso enfrentar os erros, as falhas, o envelhecimento. Enfim, existe um processo que pode ser gerador de sofrimento no enfrentamento do sujeito bailarino com a organização do trabalho.

Ao analisar as falas dos bailarinos houve a preocupação de focar aquilo que expressasse o coletivo dos entrevistados. Foi possível observar duas expressões utilizadas, com freqüência, por este grupo para informar como fazem para lidar com o sofrimento no trabalho: "eu ligo o profissional" e "o bailarino tem ego". Ao ouvir repetidas vezes essas expressões nos perguntamos qual o seu sentido. Enfim, o que os bailarinos estavam tentando nos comunicar ao utilizar estas expressões? 

bailarinos as procuravam, espontaneamente, durante o processo de observação para mostrar e contar sobre as partes doloridas de seus corpos. Não houve um dia se quer das visitas ao BCSP que um bailarino não viesse as informar sobre o quão dolorido estava. Desta forma, foi inevitável perguntar sobre o sentido deste comportamento e o que este grupo de profissionais estava tentando expressar.

\title{
A."Eu ligo o profissional"
}

Ao analisar as entrevistas, observou-se que as expressões "eu ligo o profissional", "eu me atenho ao profissional", eram recorrentes na fala dos entrevistados. Os bailarinos utilizavam tal expressão para explicar como faziam para lidar com as frustrações vivenciadas no cotidiano do trabalho. Frustrações oriundas de variadas situações : ao não serem escolhidos para o primeiro elenco, quando são substituídos no decorrer do processo de construção da coreografia, ou ainda, quando devem interpretar um projeto coreográfico com o qual não se identificam.

\begin{abstract}
(...) o principal é você manter a cabeça, (...) você lembrar que o mais importante é o lado profissional (...) e se manter tranqüilo, e ainda dentro do processo, mesmo tendo sido excluído (bailarino II, BCSP, 29/06/08).

Você liga o profissional. (...) na quinta feira passada, quando acabou o ensaio eu brochei total. Eu estava super a fim de fazer, super me dedicando e dei uma brochada. Falei : "bom, vou ser profissional ao máximo". Você se agarra à técnica (...) e faz o seu trabalho (bailarina II, BCSP, 01/07/08).

(...) Eu me atenho ao lado profissional. (...) estão precisando desse serviço meu, e eu vou dar somente esse serviço. É óbvio que eu sei que posso dar mais, inclusive a direção sabe que eu posso dar mais (bailarino I, BCSP, 13/06/08).
\end{abstract}

47 As falas acima expressam como esses bailarinos fazem para lidar com sofrimentos cotidianos no trabalho. Ao ouvir dos bailarinos a expressão "Ligar o profissional", as autoras passaram a escutar uma tentativa desses trabalhadores de minimizarem o sofrimento no trabalho colocando-se da maneira mais econômica possível na ação; somente como profissional.

\section{B.“O bailarino tem ego"}

o bailarino tem como instrumento, principal, de trabalho o corpo. Observa-se uma constante procura desse trabalhador por um corpo estética e tecnicamente perfeito, pois assim este lhe permite um movimento virtuoso. No entanto, o seu instrumento de trabalho - corpo - é, naturalmente, instável. o corpo pode falhar, apesar das inúmeras tentativas dos bailarinos e da própria organização do trabalho em controlá-lo. Assim, algumas ameaças se colocam de forma permanente, tais como a lesão inesperada, o não conseguir realizar a coreografia - seja por um limite biológico ou cronológico (o envelhecimento) - e até mesmo por questões não objetivas, pois o corpo é, também, subjetividade; os sentimentos e emoções o afetam e não existem dissociadas dele. 0 trabalho da dança tem uma dimensão imprevisível, incontrolável. Esses trabalhadores travam uma luta constante à procura da perfeição almejada, com um instrumento de trabalho naturalmente limitado e frágil. 

Durante os ensaios está sob o olhar crítico do coreógrafo, da direção e dos colegas. É frequentemente interrompido para reelaborar os movimentos a serem corrigidos. No momento do espetáculo, somam-se os olhares do público e da crítica especializada. A exposição permanente à crítica é inerente ao trabalho do bailarino, desde o início do processo até a última etapa, o espetáculo. A permanente submissão ao julgamento do outro, a constante exposição física, somados a permanente incerteza frente aos limites do instrumento de trabalho - o corpo - possibilita afirmar que esses trabalhadores se encontram numa permanente instabilidade. A cada nova coreografia e a cada novo espetáculo o bailarino é confrontado com a sua capacidade de realizar o trabalho. fragilidade, da incerteza constrói uma tentativa de expressar uma imagem ideal de simesmo. É possível observar esta estratégia pela freqüência que os bailarinos utilizam a expressão "bailarino tem ego" para relatarem histórias sobre vivências no trabalho que se relacionavam com competitividade, o sentimento de ser preterido, pelo coreógrafo ou direção e com o sentimento de impotência em relação aos limites do corpo e ao fato de não serem somente corpo - maquina, mas de serem pessoas e assim, limitadas, frágeis e submetidas à inexorabilidade da vida.

No BCSP não tem uma hierarquia dos bailarinos, mas você tem ego. (...) Você esta despontando, de repente, vem colega que quer te ver trincado, e ai você fala hammmmmmmmm (bailarina I, BCSP, 30/05/08).

Nos bailarinos o ego atrapalha. A gente nunca se entrega (...) a uma montagem. Você já recebeu prêmio, já trabalhou em várias companhias. Então, quem é o coreógrafo para lhe falar alguma coisa ? Então, para você se entregar mesmo, você tem que deixar tudo isso para trás e isso é muito difícil (bailarino I, BCSP, 13/06/08).

São poucos os colegas que ajudam. (...) pós-operados aqui tem vários eu me vejo chorando na fisioterapia, dói pra caramba! Mas, quando eu comento : “Nossa como dói pra dobrar o joelho depois da cirurgia. Doeu o seu ?". Eu ouço: "O meu não!”. (...) Pra ele não falar deve ter uma questão aí. (...) o companheirismo (...) nem sempre se tem. (...) o bailarino tem muito ego (bailarina IV, BCSP, 10/03/09).

51 As falas acima também suscitam reflexões sobre a impossibilidade de se manter no trabalho por duas dimensões inerentes às suas regras, relativas ao corpo. Trata-se do vivenciar as temidas lesões físicas e o processo inevitável de envelhecimento, que ocorre muito precocemente na vida do bailarino. Acima dos trinta e cinco anos de idade, o bailarino, para essa companhia de dança, é compreendido em processo de envelhecimento e aos quarenta anos, provavelmente, deverá se ausentar do palco por uma demanda física (lesão, fratura ou por não desenvolver o movimento com a mesma agilidade necessária). O limite do corpo, seja pelo envelhecimento ou pelas dores e lesões, é vivenciado pelos bailarinos de maneira imposta. A dor física, as lesões, o envelhecer são vivenciadas com angústia por esse grupo. Foi possível observar que os bailarinos mais velhos, que estão se aproximando da saída, estão sofrendo com a ameaça do término, como bem resume uma das bailarinas entrevistadas :

(...) Desde os nove anos, eu me sinto bailarina. (...) Eu converso muito (...) na terapia, é como se fosse a minha carteira de identidade. (...) Eu não posso jogar isto fora da noite para o dia e mudar, fazer outra coisa... Eu, mãe de família com um filho (...) tenho um salário bom. Eu não tenho outra 
formação, como é que eu vou conseguir esse salário fazendo outra coisa?

(bailarina I, BCSP, 30/05/08). profissional, mas também em relação a sua sobrevivência. Foi possível analisar, nesta pesquisa, que o sofrimento vivenciado pela bailarina I, só é possível ser verbalizado porque ela está se aproximando do fim da carreira, já os mais jovens não verbalizam tal sofrimento, mesmo porque cultuas a imagem onipotente de si-mesmo ("ter ego") é fundamental para a manutenção desses trabalhadores na carreira.

\section{A valorização da dor}

Este coreógrafo fala que teve duas operações de joelho e depois dançou como se nada tivesse acontecido, ele tem 33 anos hoje! Eu vou fazer 32 e ainda estou dançando. Ele teve essa oportunidade de parar, mas a gente ainda dança (bailarino II, BCSP, 29/06/08.)

53 A dor física é uma constante na vivência cotidiana desses profissionais ; o corpo instrumento de trabalho - é submetido a um intenso ritmo de trabalho diário. Esta condição é reconhecida pela organização do trabalho no BCSP, que possibilita aos seus bailarinos um suporte médico e fisioterápico de proteção e prevenção à saúde física. Trabalhar com o corpo dolorido é inerente ao ofício. Os bailarinos trabalham com dor, essa é a condição natural desses profissionais. A forma aparentemente natural, banal com que os bailarinos vivenciam a dor do corpo causada pelo trabalho foi analisada por Santos e Macêdo, conforme explicitada na introdução deste artigo, como uma estratégia de defesa, face à necessidade desses trabalhadores enfrentarem e superarem a dor física para poder trabalhar (Santos, 2008).

pesquisa, no entanto, foi possível reconhecer, também, outra dimensão da dor : a sua valorização. Durante a observação do processo de construção do espetáculo os bailarinos procuravam espontaneamente as pesquisadoras para informar que estavam doloridos, que haviam sofrido lesões durante os ensaios e que mesmo assim não paravam de trabalhar. Analisou-se que esses bailarinos estavam tentando informar que reconheciam a dor e a expunham enquanto resultado previsto e necessário para a avaliação positiva de seu trabalho, de sua dedicação às suas atividades. $\mathrm{O}$ bailarino dolorido representaria, assim, um trabalhador comprometido, dedicado, envolvido com o seu trabalho. Ao valorizar as suas lesões e dores o bailarino torna visível aquilo que é invisível : o seu esforço, o seu labor.

No entanto, é necessário ressaltar que essa valorização da dor vai até o momento em que ela não extrapola as possiblidades do bailarino em exercer a sua atividade. A lesão física que afasta esse trabalhador das suas atividades cotidianas é vivenciada com muita angústia e sofrimento, sobretudo uma vez que a luta pela percepção ideal de si mesmo, do corpo-maquina é vencida, e assim o profissional se percebe frágil, impotente e sem a sua identidade profissional.

\section{Conclusão}

O corpo é o principal instrumento por meio do qual o indivíduo age no mundo. Os seres humanos aprenderam, antes mesmo de construírem seus utensílios, a se apropriarem 
da natureza por meio das técnicas do corpo. O antropólogo francês Marcel Mauss ressalta que todas as ações humanas, desde as mais simples como a posição deitada até as mais sofisticadas como a natação, constituem técnicas oriundas de um processo de aprendizado (Mauss, 2003).

O corpo é o primeiro e o mais natural instrumento do homem, ou mais exatamente, sem falar de instrumento : o primeiro e o mais natural objeto técnico, e ao mesmo tempo meio técnico, do homem, é seu corpo. (...) Antes das técnicas de instrumentos, há o conjunto das técnicas do corpo (Mauss, 2003, p. 407).

57 Cada sociedade, cada cultura têm maneiras singulares de caminhar, comer, deitar, sentar, de se reproduzir, de manifestar suas emoções conforme suas regras e costumes. o que é denominado "natural" é a aquisição, por meio da educação de técnicas codificadas do uso do corpo, segundo uma determinada sociedade e cultura. As técnicas corporais são oriundas de um aprendizado constante do homem, permeadas pelos aspectos sociais e culturais nos quais esse homem está inserido (Strazzacappa, 2006).

o trabalho da dança se utiliza do primeiro instrumento humano - o corpo. Nele se inscrevem três aspectos com os quais os bailarinos labutam cotidianamente : o corpo biológico, técnico e erógeno; este último é palco da subjetividade, do sofrimento e do prazer. Para a PDT a subjetividade não existe sem o corpo, uma vez que ela começa pelo corpo ; qualquer sentimento e afeto é vivenciado no corpo e pelo corpo, a atividade de pensar e de elaborar tem como seu combustível as experiências vivenciadas pelo corpo. Porém, o corpo referido não é somente o corpo biológico, mas o corpo habitado, vivenciado ; o corpo fenomenológico. Dessa maneira, diferencia-se o corpo biológico do corpo erógeno e considera-se, este último, representante da subjetividade; “(...) é exatamente este corpo resultante da experiência mais íntima de si e da relação com o outro que é convocado no trabalhar" (Dejours, 2004b, p. 29). No caso dos bailarinos, que tem o corpo biológico como principal instrumento de trabalho, essa relação torna-se indissociável.

O prazer em realizar o movimento e assim descobrir em si mesmo a relação entre o sujeito e o seu corpo são características dos profissionais da dança. O processo de trabalho do corpo, assim como o sentimento de co-responsabilidade pelo trabalho final, se reconhecidos os seus esforços, propiciam condições específicas de criação, de identificação com o trabalho e da realização de si mesmo. Os bailarinos são trabalhadores artistas que escolhem a dança como carreira pelo prazer de realizar o movimento e a obra artística. Em contrapartida, a dança como trabalho demanda também um processo de submissão à disciplina, à exigência da busca pela perfeição, às relações competitivas e às relações hierárquicas construídas pela organização do trabalho. A dança, como trabalho organizado no interior de uma instituição, exige desses profissionais submissão a regras, a constrangimentos, a situações que desencadeiam conflito.

Desta forma a categoria analítica estratégias de defesa elaborada pela psicodinâmica do trabalha auxilia analisar o sofrimento psíquico dos bailarinos e, sobretudo, como esses enfrentam a tal sofrimento. A estratégia de defesa observada pode ser considerada a tentativa de cindir o sujeito bailarino em dois : corpo técnico - instrumento de trabalho do corpo erógeno - subjetividade. A cisão, a ruptura psíquica, o desejo de não ter que entrar em contato com o limite, com a impossibilidade, com a fragilidade inerente ao 
trabalho realizado. "Ligar o profissional", "ter ego", valorizar a dor são tentativas de não sucumbir frente ao sofrimento vivenciado e se manter trabalhando. Tal estratégia, estaria, conforme a PDT propõe, a serviço da manutenção desses bailarinos numa organização na qual o ritmo de trabalho é intenso, a pressão pela perfeição é constante, a disciplina é uma ordem, a obediência é uma premissa, a competitividade é permanente e a ameaça de exclusão paira sob esses bailarinos cotidianamente. Além disso, soma-se a estas condições, o fato que o único instrumento de trabalho desses profissionais é o seu próprio corpo. Corpo este que lesiona e envelhece. Cada bailarino é cobrado individualmente pela manutenção do seu instrumento de trabalho; este tem que estar magro, flexível, forte e apto para qualquer demanda da organização.

61 As estratégias de defesa engendradas por um coletivo de trabalhadores são construções psíquicas inconscientes, que permitem aos trabalhadores se submeterem a regras e constrangimentos da organização do trabalho. Os efeitos deletérios da organização do trabalho serão vivenciados por todos os membros de um determinado coletivo de trabalho, e a elaboração das estratégias de defesa contra esse sofrimento é empreendida por todos os envolvidos, mas de maneira inconsciente, no sentido de que não se percebe a sua construção e tão pouco se tem claro contra o que ela se manifesta. O sofrimento é, assim, vivenciado como sendo algo individual e um conflito próprio de cada trabalhador (Dejours, 1987, 2004a). Enfim, são raros os coletivos de trabalho cujos membros se percebem portadores de uma mesma estratégia de defesa face ao mesmo sofrimento. Desta forma, pode-se concluir que as estratégias de defesa, paradoxalmente, também bloqueiam a reflexão e a possibilidade de articulação coletiva contra os malefícios do trabalho. No grupo de trabalhadores analisados, esta perspectiva proposta pela PDT, foi possível de ser verificada. A forma como o trabalho é organizado, as relações de competição impostas que terminam por não fortalecer os coletivos de trabalho levam os bailarinos a sofrerem individualmente e a não atribuírem esse sofrimento como fruto da organização do trabalho. A identificação do caráter coletivo desse sofrimento poderia fortalecer o coletivo de trabalho, desenvolver processos de reconhecimento e cooperação e diminuir o sofrimento imposto a todos.

\section{BIBLIOGRAFIA}

Bardin, L. (1977). Análise de conteúdo. Lisboa : Edições 70.

Becker, H. S. (2006). Les mondes de l'art. Paris : Flammarion.

Billiard, I. (2001).Sante Mentale et Travail : L'Emergence de la Psychopathologie du Travail. Paris : La Dispute.

CBO (2002). Relatório do Ministério do Trabalho e Emprego do Brasil de Classificação Brasileira de Ocupações. Retirado em janeiro, 10, 2011, de www.mtecbo.gov.br.

Dejours, C (1987). A Loucura do Trabalho. São Paulo : Oboré.

Dejours, C. (1999) A banalização da injustiça social. Rio de Janeiro : FGV. 
Dejours, C. (2004a). Addendum : da psicopatologia do trabalho à psicodinâmica do trabalho. In : Selma Lancman ; Laerte Sznelwar (Orgs.). Christophe Dejours : da psicopatologia à psicodinâmica do trabalho (pp. 47-104). Brasília, Paralelo.

Dejours, C. (2004b). Subjetividade, trabalho e ação. Revista de Produção, 14, 3, 27-34.

Dejours, C. \& Bègue, F. (2010). Suicídio e trabalho : o que fazer ? Brasília : Paralelo 15.

Gadelha, R. C. P. (2006). A dança possível : as ligações do corpo numa cena. Fortaleza : Expressão Gráfica e Editora Ltda.

Lancman, S. \& Uchida, S. (2003). Trabalho e subjetividade : o olhar da psicodinâmica do trabalho. Cadernos de Psicologia Social do Trabalho, 6, 79-90.

Laplanche, J. \& Pontalis, JB. (2001). Vocabulário da psicanálise. São Paulo : Editora Martins Fontes. Mauss, M. (2003). Sociologia e antropologia. São Paulo : Cosac \& Naify.

Menger, P. M. (2005). Retrato do artista enquanto trabalhador - metamorfoses do capitalismo. Lisboa : Roma Editora.

Prigent, H. (2005). Melancolie : les metamorphoses de la dépression. Paris : Découvertes Gallimard/ Réunion des Musées Nationaux.

Rannou, J., \& Roharik, I. (2006). Les danseurs : un métier d'engagement. Paris : La Documentation Française, (Collection Questions de Culture).

Santos, E.A. (2008). O trabalho dos bailarinos profissionais de uma companhia de dança contemporânea : uma perspectiva psicodinâmica. Dissertação de mestrado. Faculdade de Psicologia, Pontifícia Universidade Católica de Goiás, Goiânia.

Schmid-Kitskis, E. (2002). Défense (mécanismes de -). In : Alain de Mijolla. (dir). Dictionnaire international de la psychanalise. (pp. 427-428). Paris : Calmann-Lévy.

Segnini, L. R. P. (2007). Criação rima com precarização : análise do mercado de trabalho artístico no Brasil. In : Anais do XIII Congresso Brasileiro de Sociologia (pp. 1-38). Recife, Brasil.

Segnini, L. R. P. (2008). Relações de Gênero nas profissões artísticas : comparação Brasil-França. In : Albertina de Oliveira Costa ; Bia Sorj ; Cristina Bruschini ; Helena Hirata (Org). Mercado de trabalho e gênero :comparaçôes internacionais (pp. 337-354). Rio de Janeiro : Editora da FGV.

Segnini, L. R. P. (2009). La production d'un spetacle vivant - rapports sociaux entre musique et dance. In : Actes du Colloque : 25 ans de Sociologie de la Musique en France :ancrages thèoriques et rayonnement international (pp. 2-60). Université Paris Sorbonne, Paris.

SegninI, L. R. P. (2010). Vivências heterogêneas do trabalho precário : homens e mulheres, profissionais da música e da dança, Paris e São Paulo. In : Nadya Guimarães ; Helena Hirata ; Kurumi Sugita (Org.). Trabalho flexível, empregos precários ? Uma comparação Brasil, França e Japão (pp. 169-202). São Paulo : EDUSP.

SegninI, M. P. (2006). L'artiste du spectacle vivant au temps de l'intermittence : plaisir et souffrance au travail. Master recherche. Conservatoire National des Arts et Métiers-CNAM, Paris.

Segnini, M. P. (2010). Sofrimento e prazer no trabalho artístico em dança. Dissertação de mestrado. Faculdade de Medicina da Universidade de São Paulo, São Paulo.

Strazzacappa, M. (2001). A educação e a fábrica de corpos : a dança na escola. Cadernos Cedes. 53, 69-83. 
Strazzacappa, M. (2006). O corpo e suas representações : As técnicas de educação somática na preparação do artista cênico. IN : Marcia Strazzacappa ; Carla Morandi. Entre a arte e a docência : a formação do artista da dança (pp. 39-54). Campinas : Papirus (Coleção Ágere).

Vergara, S. C. (2006). Métodos de pesquisa em administração. São Paulo : Editora Atlas.

Wittkower, R., \& Wittkower, M. (1991). Les enfants de saturne : psychologie et comportment des artistes de l'Antiquité à la Revolution Française. Paris : Editions Macula.

\section{RESUMOS}

Este artigo se insere no âmbito dos estudos que articulam trabalho e saúde mental. o objetivo deste artigo foi analisar a relação entre o trabalhador bailarino e a organização do trabalho em dança à luz do constructo teórico da psicodinâmica do trabalho (PDT). 0 foco desta análise foram as maneiras pelas quais os trabalhadores da dança mobilizam suas subjetividades ao buscar realizar suas atividades laborais cotidianas, no Balé da Cidade de São Paulo, companhia de dança pública vinculada ao Theatro Municipal de São Paulo (Brasil). A partir de um estudo qualitativo realizado através de entrevistas e observação do processo de trabalho, procurou-se compreender as estratégias mobilizadas subjetivamente pelos bailarinos ao enfrentar o sofrimento vivenciado no trabalho. Pode-se concluir que entre as estratégias encontradas por este grupo de trabalhadores está a busca de uma cisão entre o corpo biológico, exercitado de forma técnica e utilizado como, instrumento de trabalho, e o corpo erógeno palco das vivencias subjetivas.

Este artículo se inserta en el ámbito de los estudios que articulan trabajo y salud mental. Su objetivo fue analizar la relación del bailarín y la organización de trabajo en danza a la luz del constructo teórico de la psicodinámica del trabajo (PDT). Este análisis se enfoca en las maneras a través de las que los trabajadores de la danza movilizan sus subjetividades al buscar realizar sus actividades laborales cotidianas en el Ballet de la Ciudad de São Paulo, compañía pública de danza vinculada al Teatro Municipal de São Paulo (Brasil). A partir de un estudio cualitativo, realizado a través de entrevistas y observación del proceso de trabajo, se buscó comprender las estrategias movilizadas subjetivamente por los bailarines al enfrentar el sufrimiento vivido en el trabajo. Se puede concluir que entre las estrategias encontradas por este grupo de trabajadores, está la búsqueda de una escisión entre el cuerpo biológico ejercitado de forma técnica y utilizado como instrumento de trabajo y el cuerpo erógeno, escenario de las vivencias subjetivas.

Cet article s'insère dans le domaine des études qui articulent travail et santé mentale. L'objectif a été d'analyser la relation entre le travailleur danseur et l'organisation du travail en danse à la lumière des concepts de la psychodynamique du travail (PDT). Au centre de cette analyse se trouvent les manières dont les travailleurs de la danse mobilisent leurs subjectivités lorsqu'ils tentent de réaliser leurs activités de travail quotidiennes, dans le Balé da Cidade de São Paulo, compagnie de danse publique liée au Theatro Municipal de São Paulo (Brésil). À partir d'une étude qualitative développée sur la base d'entretiens et de l'observation du processus de travail, nous avons cherché à comprendre les stratégies mises en place par les danseurs lorsqu'ils se confrontent à la souffrance vécue au travail. On peut conclure qu'au sein des stratégies de ce groupe de travailleurs, se trouve la recherche d'une scission entre le corps biologique, exercé sur un mode technique et utilisé comme instrument de travail, et le corps érogène, lieu des expériences subjectives.

The present article is part of a series of studies that articulate work and mental health. The aim is to analyze the relationships between the dance workers and the organization of dance as a work in light of the psychodynamic of work theory. This analysis focuses on the way dance workers 
mobilize their subjectivity while performing their daily work activities in Balé da Cidade de São Paulo (São Paulo City Ballet), a public dance company linked to the Theatro Municipal de São Paulo in Brazil (São Paulo City Theatre). We aimed at understanding the strategies that are subjectively mobilized by the dancers when facing suffering due to work based on a qualitative study conducted through interviews and personal observation of the work process. We concluded that one of the strategies adopted by this group of workers is the quest for a split between the biological body, which is exercised on a technical way and used as a work tool, and the erogenous body, that houses the subjective experiences.

\section{ÍNDICE}

Palabras claves: salud mental, trabajo, danza, sufrimiento

Keywords: mental health, work, dance, suffering

Palavras-chave: saúde mental, trabalho, dança, sofrimento

Mots-clés: santé mentale, travail, danse, souffrance

\section{AUTORES}

\section{MARINA PETRILLI SEGNINI}

Faculdade de Medicina da Universidade de São Paulo, Departamento de Fisioterapia, Fonoaudiologia e Terapia Ocupacional, R. Cincinato Braga, 184, apto 51, CEP. 01333-010. São Paulo, SP-Brasil marsegnini@gmail.com

\section{SELMA LANCMAN}

Faculdade de Medicina da Universidade de São Paulo, Departamento de Fisioterapia, Fonoaudiologia e Terapia Ocupacional, R. Cincinato Braga, 184, apto 51, CEP. 01333-010. São Paulo, SP-Brasil

lancman@usp.br 